\title{
A\&L
}

ISSN 2709-0205

Vol 1 Issue 1 (2020)

\section{The influence of quercetin on the functional state of platelets and the viscosity of blood among the aged people with the metabolic syndrome}

\author{
O.V. Korkushko, S.S. Naskalova, I.A. Antonyuk-Shcheglova, G.V. Duzhak, O.V. Bondarenko , O.M. Grib, \\ V.B. Shatylo \\ State Institution “D. F. Chebotarev Institute of Gerontology NAMS of Ukraine”, Kyiv, Ukraine \\ Correspondence: naskalov@bigmir.net
}

Received: 15.01.2020; Accepted: 05.03.2020; Published: 07.07.2020

\begin{abstract}
The purpose of this research was to study the effect of quercetin on the functional state of platelets and blood viscosity among the aged patients with the metabolic syndrome (MS). 110 patients with MS in the age of 60-75 years were divided equally into the main and control groups. The patients of the main group received quercetin for 3 months (drug "Quertin", chewable tablets produced by private joint stock company scientific-productional centre "Borschagovsky chemical pharmaceutical plant") in dose $80 \mathrm{mg} 3$ times per day. The examined subjects from the control group were treated with placebo for the same time. Before and after the course of treatment, MS criteria were evaluated, platelet aggregation capacity, blood viscosity, and serum lipid levels were determined. After course treatment with quercetin, the rheological properties of blood were improved: its viscosity, spontaneous and induced aggregation of the platelets were decreased. A statistically significant decrease of total cholesterol and low density lipoprotein (LDL) cholesterol in serum was observed. Correlation analysis showed that the improvement of blood viscosity was due to the favorable changes in the lipid spectrum and a decrease of the aggregation capacity of platelets. Thus, the obtained results indicate that the use of course of quercetin by the aged patients with metabolic syndrome (within 3 months) reduces the manifestation of dyslipidemia, increased spontaneous and induced platelet aggregation, contributes to the increase of erythrocyte deformity index that together lead to a decrease of blood viscosity as one of the risk factors for complications of metabolic syndrome.
\end{abstract}

Key words: Metabolic syndrome, old age, quercetin, blood viscosity, platelet aggregation capacity.

It is known that age-related changes in the organism, especially those that are accompanied by the development of pathology, accelerate the aging process and create the preconditions for the formation of cardiovascular diseases, metabolic syndrome (MS) and type 2 diabetes mellitus (DM) $[1,4,16]$.

One of the indicators of age-related changes is an increase of blood viscosity - an important rheological parameter that depends on plasma (blood lipids and fibrinogen content) and cellular factors (aggregation and deformation capacity of erythrocytes, adhesive-aggregation properties of platelets) [2, 3, 5, 10].

The detection rate of metabolic syndrome, which is a common pathology in many countries of the world, including Ukraine, is increasing with age. One of the components of MS is a disorder of the rheological properties of the blood, the combination of which with such components of MS as insulin resistance, visceral obesity, arterial hypertension, dyslipidemia, carbohydrate metabolism disorder, endothelial dysfunction, chronic inflammation many times increases cardiovascular risk and is associated with increased morbidity and mortality from the cardiovascular pathology and type 2 DM [11, 12, 17].

Each component of the metabolic syndrome is an independent risk factor for cardiovascular pathology, but their combination for one person increases this risk much more times than in a case of the sum of the individual components [9]. 
A large amount of data, indicating the important role of oxidative stress for the development of metabolic syndrome, has been accumulated, which makes expediency of using of the antioxidant drugs for its correction. One of the perspective directions is the use of herbal antioxidants that combines high efficacy with the absence of expressive side effects. In particular, it is advisable to use the compounds from a number of flavonoids for the prevention and treatment of the metabolic syndrome, diabetes and its complications.

Quercetin is the most common representative of the flavonoids that is considered to be a potential compound for the prevention of cardiovascular disease. Most studies of quercetin are related to its antioxidant properties, its influence on the various enzyme systems and biological pathways that determine carcinogenesis, inflammation, and cardiovascular diseases $[8,14]$.

There is an information that quercetin inhibition of platelet aggregation in animals, is due to the influence on the processes of thromboxane formation, reduction of total cholesterol and increase of the high density lipoproteins cholesterol level [15]. During the studying of the effectiveness of the medicinal product, which included quercetin, potassium and magnesium salts, among the people with MS in the age group of 30-50 years favorable changes in blood viscosity and level of malondialdehyde were revealed [6].

In addition, the positive influence of quercetin on the rheological and antiaggregation properties of blood due to its antioxidant and membrane stabilizing effects has been proved. Quercetin discourages the quantitative and qualitative changes of lipids in the membranes of blood cells (both erythrocytes and platelets), reduces their aggregation properties, prevents the reaction of release of coagulation factors from them, and in such a way, contributes to the reduction of coagulation potential and the normalization of blood potential.

However, there is no data in the literature regarding the influence of quercetin on the functional status of platelets and blood viscosity among the aged people with MS.

\section{Materials and methods}

110 patients with metabolic syndrome in the age of 60-74 years were involved in the study. The study was conducted in accordance with the laws of Ukraine and the principles of the Declaration of Human Rights in Helsinki. The examination program, information for the patients and informed consent form were agreed by the medical ethics committee of the Clinical Department of the State Institution "D.F. Chebotaryov Institute of Gerontology NAMS of Ukraine" (Protocol №11 of June 17, 2016).

Metabolic syndrome was diagnosed in accordance with the recommendations of ATP III (2001) with the detection of three or more criteria: 1) waist circumference for the men is greater than $102 \mathrm{~cm}$ and for the women is greater than $88 \mathrm{~cm}$; 2) triglyceride level is above $1.7 \mathrm{mmol} / \mathrm{l}$; 3) high density lipoprotein cholesterol (HDL cholesterol) for the men is less than $1.03 \mathrm{mmol} / 1$ and for the women is less than $1.29 \mathrm{mmol}$ / 1; 4) systolic blood pressure is above $130 \mathrm{~mm} \mathrm{Hg}$ and (or) diastolic blood pressure is greater than $85 \mathrm{~mm}$ $\mathrm{Hg}$; 5) fasting plasma glucose level is exceeding $6.1 \mathrm{mmol} / 1$.

Selected 110 patients with MS who had no serious clinical pathology of other organs and systems (uncontrolled arterial hypertension, diabetes, acute cerebrovascular disorders, congenital and acquired cardiac abnormalities, moderate and severe renal failure, diffuse connective tissue diseases) and who gave their written consent to participate in the study were equally divided into the main and control groups.

Angiotensin converting enzyme (ACE) inhibitors, statins, and antiplatelet agents acetylsalicylic acid (75 - $100 \mathrm{mg}$ daily) were taken as baseline therapy for both groups at least for one month before inclusion in the study and throughout the study.

The patients of the main group during three months took the drug "Quertin" (chewable tablets manufactured by PJSC SPC "Borschagovsky chemical pharmaceutical plant") $80 \mathrm{mg}$ (2 tables.) 3 times per day.

Patients from the control group received placebo ( 2 tablets 3 times per day during 3 months). In order to get the objective evaluation of the effectiveness of quercetin, patients were not advised to take medications and biological supplements that could potentially affect the dynamics of the studied parameters.

Most of the examined patients from the main and the control groups (84.5\%) had three out of five criteria for metabolic syndrome. $13 \%$ of them identified 4 criteria and $2.7 \%$ identified five criteria of MS. There were no differences between both groups at the stage of inclusion in the study. 
Indicators of blood viscosity, platelet aggregation capacity and serum lipids were determined after randomization before prescribing of quercetin / placebo and after three months of taking of these drugs.

Blood viscosity was determined using an ACR-2 rotary viscometer (Russia) at shear rates of 10-200 s1 , and the erythrocyte aggregation capacity and deformation were calculated using the deformation index (IDE) and erythrocyte aggregation index (IAE). IAE was calculated as the ratio of blood viscosity at a shear rate of $20 \mathrm{~s}^{-1}$ and a blood viscosity at a shear rate of $100 \mathrm{~s} \mathrm{~s}^{-1}$. IDE is the ratio of blood viscosity at a shear rate of $100 \mathrm{~s}^{-1}$ and a shear rate of $200 \mathrm{~s}^{-1}$.

Platelet aggregation activity was studied on a two-channel laser platelet aggregation analyzer («Biola», Russian Federation) using turbidometric method. Blood sampling for the study was carried out in a silicone test tube with a 3.8\% sodium citrate solution in a volume ratio of $1: 9$ (final concentration of citrate in the test tube $0.38 \%$ ). After sampling, the blood-citrate mixture was centrifuged at $165-200 \mathrm{~g}$ (that is corresponding to $1000 \mathrm{rpm}$ ). The obtained platelet-rich plasma was collected in a clean plastic test tube and subsequently used to study the platelet aggregation.

The level of spontaneous and induced platelet aggregation was evaluated. Adelosine diphosphate (ADPs) at a final concentration of $5 \mu \mathrm{mol} / 1$ and adrenaline at a final concentration of $1 \mu \mathrm{mol} / 1$ were used as inductors. On the curves of light transmission the degree of platelet aggregation was evaluated.

To evaluate lipid metabolism, the level of total cholesterol, high density lipoprotein (HDL), low density lipoprotein (LDL) and very low density lipoprotein (VLDL) cholesterol, triglycerides (TG) in serum has been determined by standard biochemical methods on the automatic biochemical analyzer «Autolab» by «Boehringer Mannheim».

Considering that the data obtained had a distribution close to normal, the data was presented in $\mathrm{M} \pm$ $\mathrm{m}$ format. Statistical processing of the obtained data was performed using the program «Statistica 6.0» for Windows (StatSoft, USA). The probability of difference between groups was estimated using the t-test (by Student). The differences were considered significant at $\mathrm{p}<0.05$. One-factor discriminant analysis and Pearson correlation analysis were carried out (the results were considered to be significant at $\mathrm{p}<0.05$ ).

\section{Results and discussion}

\section{Influence of course taking Quertin on blood viscosity and platelet aggregation capacity}

In patients with MS, as a result of glycation of proteins, in particular hemoglobin, blood rheological parameters are changing: the elasticity and motility of erythrocytes are reduced, platelet aggregation activity and blood viscosity are increased $[7,9]$.

After course treatment with quercetin among the aged patients with MS, the rheological blood properties of blood were improved, that is evidenced by statistically significant decrease of blood viscosity at different displacement rates, index of erythrocyte aggregation ability (RBC aggregation), and increase of erythrocyte deformity index (RBC deformability) (tab. 1).

Table 1

Indices of blood viscosity before and after the course treatment with quercetin or placebo $(\mathrm{M} \pm \mathrm{m})$

\begin{tabular}{|c|c|c|c|c|c|}
\hline \multicolumn{2}{|c|}{ Indicators } & \multicolumn{2}{|c|}{ Control group $(n=55)$} & \multicolumn{2}{|c|}{ Main group $(n=55)$} \\
\hline & & Before treatment & After treatment & Before treatment & After treatment \\
\hline \multirow{5}{*}{$\begin{array}{l}\text { Displaceme } \\
\text { nt rates }\end{array}$} & $200 \mathrm{sec}^{-1}$ & $3.95 \pm 0.05$ & $3.85 \pm 0.05$ & $3.95 \pm 0.05$ & $3.73 \pm 0.05 *$ \\
\hline & $100 \mathrm{sec}^{-1}$ & $4.07 \pm 0.04$ & $3.99 \pm 0.04$ & $4.07 \pm 0.04$ & $3.89 \pm 0.05 *$ \\
\hline & $50 \mathrm{sec}^{-1}$ & $4.42 \pm 0.05$ & $4.34 \pm 0.05$ & $4.44 \pm 0.05$ & $4.21 \pm 0.05$ * \\
\hline & $20 \mathrm{sec}^{-1}$ & $4.75 \pm 0.05$ & $4.58 \pm 0.08$ & $4.79 \pm 0.05$ & $4.47 \pm 0.08^{* *}$ \\
\hline & $10 \mathrm{sec}^{-1}$ & $4.92 \pm 0.05$ & $4.79 \pm 0.06$ & $4.95 \pm 0.05$ & $4.67 \pm 0.05^{* *}$ \\
\hline \multirow{2}{*}{\multicolumn{2}{|c|}{$\begin{array}{l}\text { RBC aggregation } \\
\text { RBC deformability }\end{array}$}} & $1.03 \pm 0.00$ & $1.03 \pm 0.00$ & $1.03 \pm 0.00$ & $1.04 \pm 0.00^{* *}$ \\
\hline & & $1.16 \pm 0.00$ & $1.16 \pm 0.00$ & $1.17 \pm 0.00$ & $1.15 \pm 0.00^{* *}$ \\
\hline
\end{tabular}

Notes: the siguificance of changes under the influence of the treatment: ${ }^{*}-p<0.01$; ${ }^{* *}-p<0.001$. 
The effect noticed among the majority (74\%) of the patients in the main group. In the control group of patients (who were on a placebo) there were no changes.

The decrease of the platelet aggregation ability, both spontaneous and induced aggregation, indicates the improvement of the rheological properties of blood (tab. 2).

The decrease of platelet aggregation ability was observed among the most patients, who took quercetin: in 42 out of $55(76 \%)$ spontaneous aggregation was reduced, in 48 out of $55(87 \%)$ - adrenaline-induced aggregation was reduced, in 46 out of 55 (84\%) - ADF-induced platelet aggregation was reduced.

In the control group, a little statistically insignificant decrease in the indices of spontaneous and induced platelets aggregation was noted.

Table 2

Indices of aggregation ability of platelets before and after the course treatment with quercetin or placebo $(\mathrm{M} \pm \mathrm{m})$

\begin{tabular}{|l|c|c|c|c|}
\hline \multirow{2}{*}{ Indicators } & \multicolumn{2}{|c|}{ Control group (n=55) } & \multicolumn{2}{c|}{ Main group (n=55) } \\
\cline { 2 - 5 } & Before treatment & After treatment & Before treatment & \\
\cline { 2 - 5 } & & & $3.36 \pm 0.30$ & $2.57 \pm 0.15^{*}$ \\
\hline Spontaneous platelets aggregation, $\%$ & $4.07 \pm 0.29$ & $61.5 \pm 2.66$ & $63.59 \pm 2.2$ & $56.05 \pm 1.74^{*}$ \\
\hline Adrenaline-induced platelets & $66.18 \pm 2.61$ & & 6.26 & \\
\hline aggregation, $\%$ & & $61.11 \pm 2.75$ & & $54.72 \pm 1.79^{*}$ \\
\hline ADF-induced platelets aggregation, $\%$ & $65.53 \pm 2.74$ & & & \\
\hline
\end{tabular}

Notes: the siguificance of changes under the influence of the treatment: ${ }^{*}-\mathrm{p}<0.01$.

The influence of the course treatment with quercetin on the indices of the lipid profile of blood serum

Dislipidemiya is an important criterion for the diagnosis of MS, that is fairly considered to be an atherosclerosis high risk factor.

Taking of quercetin had led to the favorable changes in the lipid spectrum of blood serum among the majority aged patients with MS.

In particular, a course taking of quercetin, have contributed to a statistically significant decrease of the levels of total cholesterol, low density lipoprotein cholesterol (LDL cholesterol) and atherogenicity index (AI) (tab. 3). In 35 cases from 55 (84\%) of the patients, there was a fall of concentration of the total cholesterol and LDL cholesterol.

Among the patients of the control group the blood serum lipids have not been changed significantly. Moreover, it was observed the slight level of increase of the total cholesterol and LDL cholesterol levels.

The changes of HDL - cholesterol levels were multidirectional in both groups. Among the patients of the main group a tendency to increase was observed, but in the control group the level of HDL - cholesterol had a downward trend.

Table 3

Indices of the lipid spectrum of blood serum before and after the course treatment with quercetin or placebo $(\mathrm{M} \pm \mathrm{m})$

\begin{tabular}{|c|c|c|c|c|}
\hline \multirow[t]{2}{*}{ Indicators } & \multicolumn{2}{|c|}{ Control group $(\mathrm{n}=55)$} & \multicolumn{2}{|c|}{ Main group $(n=55)$} \\
\hline & Before treatment & After treatment & Before treatment & After treatment \\
\hline Total cholesterol, $\mathrm{mmol} / \mathrm{L}$ & $5.77 \pm 0.14$ & $5.58 \pm 0.15$ & $5.97 \pm 0.14$ & $5.53 \pm 0.15^{*}$ \\
\hline Triglycerides, $\mathrm{mmol} / \mathrm{L}$ & $1.27 \pm 0.06$ & $1.22 \pm 0.07$ & $1.34 \pm 0.07$ & $1.24 \pm 0.07$ \\
\hline $\begin{array}{l}\text { high density lipoprotein (HDL), } \\
\mathrm{mmol} / \mathrm{L}\end{array}$ & $1.59 \pm 0.03$ & $1.56 \pm 0.03$ & $1.55 \pm 0.03$ & $1.59 \pm 0.03$ \\
\hline $\begin{array}{l}\text { Low density lipoprotein (LDL), } \\
\mathrm{mmol} / \mathrm{L}\end{array}$ & $3.63 \pm 0.13$ & $3.44 \pm 0.16$ & $3.82 \pm 0.16$ & $3.41 \pm 0.14^{*}$ \\
\hline $\begin{array}{l}\text { Very low density lipoprotein } \\
\text { (VLDL), mmol/L }\end{array}$ & $0.52 \pm 0.02$ & $0.50 \pm 0.03$ & $0.60 \pm 0.03$ & $0.55 \pm 0.03$ \\
\hline Atherogenicity index & $2.68 \pm 0.10$ & $2.65 \pm 0.12$ & $2.88 \pm 0.12$ & $2.51 \pm 0.10^{*}$ \\
\hline
\end{tabular}

Notes: the siguificance of changes under the influence of the treatment: ${ }^{*}-\mathrm{p}<0.01$. 
In the research works of some intvestigators it is established that the changes of the concentration of blood lipids, in particular, increasing of the level of cholesterol can influence on the indices of blood viscosity, change the laminar nature of blood flow to turbulent and also increase the viscosity of the plasma itself [3]. It is possible to allow that the beneficial effect of quercetin on blood viscosity is partially conditioned due to its normalizing effect on the lipid composition of blood serum - reduction of the level of cholesterol. Thus, Tang L.Q and others (2006) explain the inhibitory effect of quercetin on the process of platelets aggregation in animals with aloxane diabetes with fall of the concentration of the total cholesterol [15].

Moreover, among the main factors that are creating a phenomenon of viscosity there are volume concentration of red blood cells, composition of blood plasma, cellular aggregation and deformation of the cellular elements. That's why the obtained by ourselves the beneficial effect of quercetin on the viscosity of blood, is due to decrease of the indices of spontaneous and induced platelets aggregation, as well as increase of the index of deformity of erythrocytes. As an evidence of this, there are identified direct correlations between indices of blood viscosity and spontaneous aggregation $(r=0.55)$, adrenaline-induced aggregation $(\mathrm{r}=0.66)$, ADF- induced aggregation $(\mathrm{r}=0.62)$, and negative correlation between blood viscosity and the index deformity of erythrocytes $(r=-0.69)$.

Summarizing the received results, it can be approved that among the aged patients with metabolic syndrome the course treatment (within 3 months) with quercetin reduces the manifestation of dyslipidemia, increased spontaneous and induced platelet aggregation, contributes to the increase of the index of deformation of erythrocytes, which leads to a decrease in blood viscosity.

\section{Conclusions}

1. After the course treatment with quercetin the improvement of rheological properties of the blood among the aged patients with metabolic syndrome was observed: the indices of blood viscosity, spontaneous and induced platelet aggregation were decreased.

2. After the course treatment with of quercetin there were a statistically significant decrease of total cholesterol and LDL cholesterol levels in blood serum.

3. Quercetin decreases blood viscosity by improving the serum lipid spectrum and reducing of the aggregation capacity of platelets and erythrocytes.

Author Contributions: All authors participated equally in writing this commentary.

Conflicts of Interest: The authors declare no conflict of interest.

Information about Authors:

Oleg V. Korkushko - DSc (Medicine), Prof., Cor. Member of the NAS of Ukraine, Full Member of the NAMS of Ukraine, Head of the Department of Clinical Physiology and Pathology of Internal Organs; https://orcid.org/0000-0001-6577-8647

Svitlana S. Naskalova - PhD (Medicine), Senior Researcher of the Department of Clinical Physiology and Pathology of Internal Organs; https://orcid.org/0000-0001-9518-2633

Ivanna A. Antonyuk-Shcheglova - DSc (Medicine), Leading Researcher of the Department of Clinical Physiology and Pathology of Internal Organs; https://orcid.org/0000-0002-6122-8266

Georgij V. Duzhak - PhD (Medicine), Senior Researcher of the Department of Clinical Physiology and Pathology of Internal Organs; https://orcid.org/0000-0003-0320-4263

Olena V. Bondarenko - PhD (Medicine), Senior Researcher of the Department of Clinical Physiology and Pathology of Internal Organs; https://orcid.org/0000-0002-2229-3719

Oksana M. Grib - MD, PhD (Medicine), Department of Clinical Physiology and Pathology of Internal Organs

Valeri B. Shatilo - DSc (Medicine), Prof., Leading Researcher of the Department of Clinical Physiology and Pathology of Internal Organs, Deputy Director for Research; https://orcid.org/0000-0001-6420-000X 


\section{References}

1. Anisimov, V.N. Molekulyarnyye i fiziologicheskiye mekhanizmy stareniya [Molecular and physiological mechanisms of aging (in Russian) ]. Nauka: St. Petersburg, 2003; p 468.

2. Berkovsky, A.L. Posobiye po izucheniyu adgeziono-agregatsionnoy aktivnosti trombotsitov (uchebnoye posobiye) [A manual on the study of adhesive aggregation activity of platelets (educational manual) (in Russian)]. Berkovsky, A.L.; Vasiliev, S.A.; Zherdeva, L.V., Ed. Moscow, 2002; p 62.

3. Volkov, V.I. Trombotsitarnyy gemostaz i aterogenez: patogeneticheskiye i terapevticheskiye aspekty [The platelet hemostasis and atherogenesis: pathogenetic and therapeutic aspects]. Volkov, V.I.; Zaprovalnaya, O.E., Ed. Circulation and hemostasis (in Ukraine) 2003, 1, 18-25.

4. Korkushko, O.V.; Shatilo, V.B.; Ishchuk, V.A. et al. Insulinorezistentnost' kak faktor uskorennogo stareniya organizma [Insulin resistance as a factor of accelerated aging of the organism]. Problems of aging and longevity (in Russian) 2012, 21, 3, 357-367.

5. 5. Korkushko, O.V.; Lishnevskaya, V.Y.; Duzhak, G.V. Reologicheskiye svoystva krovi pri starenii i faktory, ikh opredelyayushchiye [Rheological properties of blood during aging, and their determinants]. Circulation and hemostasis (in Ukraine) 2007, 1, 5-14.

6. Parkhomenko, A.N. \& Kozhuhov, S.N. Novyye vozmozhnosti v lechenii bol'nykh s ostrym infarktom miokarda s elevatsiyey segmenta ST: korvitin dlya in"yektsiy [New possibilities in the treatment of patients with acute myocardial infarction with elevated segment of ST: corythrin for injections]. Ukr. Med. Journal (in Russian) 2004, 2, 40, 33-37.

7. Shilov, A.M. \& Melnyk, M.V. Arterial'naya gipertoniya i reologicheskiye svoystva krovi [Arterial hypertension and rheological properties of blood (in Russian)]. "BARS": Moscow, 2005; p 206.

8. Arts, I.C.; Hollman, P.C. Polyphenols and disease risk in epidemiologic studies. Am. J. Clin. Nutr 2005, 81, 1, 317S-325.

9. Babik, B.; Peták, F.; Agócs, S. et al. Diabetes mellitus: endothelial dysfunction and changes in hemostasis. Or. Hetil. 2018, 159, 33, 1335-1345.

10. Eto, K.; Ochiai, M.; Isshiki, T., et al. Platelet aggregability under shear is enhanced in patients with unstable angina pectoris who developed acute myocardial infarction. Jpn. Circ. J. 2001, 65, 279-282.

11. Ginsberg, H. N. \& MacCallum, P. R. The obesity, metabolic syndrome, and type 2 diabetes mellitus pandemic: Part I. Increased cardiovascular disease risk and the importance of atherogenic dyslipidemia in persons with the metabolic syndrome and type 2 diabetes mellitus. J. Cardiometab. Syndr. 2009, 4, 2, 113-119.

12. Lemkes, B.A.; Hermanides, J.; Devries, J.H. et al. Hyperglycemia: a prothrombotic factor? J. Thromb. Haemost 2010, 8, 8, 1663-9.

13. Meigs, J.B.; Mittleman, M.A.; Nathan, D.M. et ai. Hyperinsulinemia, hyperglycemia, and impaired hemostasis: the Framingham Offspring Study. JAMA 2000, 283, 221-228.

14. Middleton, E. \& Kandaswami, C. The Effects of Plant Flavonoids on Mammalian Cells: Implications for Inflammation, Heart Disease, and Cancer. Pharmacol. Rev. 2000, 52, 4, 673-751.

15. Tang, L.Q.; Wei, W.; Chen, L.M.; Liu, S. Effects of berberine on diabetes induced by alloxan and a high-fat/highcholesterol diet in rats. J. Ethnopharmacol. 2006, 108, 1, 109-115.

16. 16 Williamson, R.; McNeilly, A.; Sutherland, C. Insulin resistance in the brain: An old-age or new-age problem? Biochem Pharmacol 2012, 84, 6, 737-45.

17. 17. Wilson, P.W.; D'Agostino, R.B.; Parise, H. et al. Metabolic syndrome as a precursor of cardiovascular disease and type 2 diabetes mellitus. Circulation 2005, 112, 20, 3066-3072. 